\title{
Comparative evaluation of hysterosalpingo contrast sonography with laparoscopy for determination of tubal patency in infertility
}

\author{
Geetha Krishnamoorthy ${ }^{1}$, Amutha Perumal ${ }^{1}$, Chithra Boovaragasamy², \\ Gnanamani Gnanasabai ${ }^{2 *}$
}

\begin{abstract}
${ }^{1}$ Department of Obstetrics and Gynecology, Vinayaka Missions Medical College and Hospital, Karaikal, Puducherry, India

${ }^{2}$ Department of Community Medicine, Vinayaka Missions Medical College and Hospital, Karaikal, Puducherry, India
\end{abstract}

Received: 23 February 2020

Accepted: 27 March 2020

\section{*Correspondence: \\ Dr. Gnanamani Gnanasabai, \\ E-mail: gnanamani00@gmail.com}

Copyright: (c) the author(s), publisher and licensee Medip Academy. This is an open-access article distributed under the terms of the Creative Commons Attribution Non-Commercial License, which permits unrestricted non-commercial use, distribution, and reproduction in any medium, provided the original work is properly cited.

\begin{abstract}
Background: Tubal factor is responsible for infertility and is found in one of three infertile women. The current research was undertaken to compare the efficacy of hysterosalpingo contrast sonography (HyCoSy) with laparoscopy and chromopertubation in infertile women.

Methods: A cross-sectional study was conducted from August 2016 to March 2017 among the patients attending outpatient department with complaints of primary or secondary infertility after obtaining written and informed consent. Detailed history of the patient was taken; clinical examination and necessary investigations were done. Data analysis was carried out using SPSS version 22.

Results: All the HyCoSy findings showed excellent specificity (84-100\%) and the sensitivity ranged from $40-87 \%$. Conclusions: Study conclude that HyCoSy is a good screening method for evaluating uterine cavity lesions and tubal block in infertile women being safe, sensitive, cost effective, non-invasive procedure giving additional information regarding ovarian, adnexal and peritoneal pathology.
\end{abstract}

Keywords: Infertility, Hysterolaparoscopy, Hysterosalpingo contrast sonography, Tubal patency

\section{INTRODUCTION}

Fallopian tubes form the gateway for transfer of gametes and embryo. Infertility is defined as failure to conceive even after one year of unprotected intercourse. ${ }^{1}$ About $90 \%$ of the couples should conceive within 12 months of unprotected intercourse. ${ }^{2}$ Tubal factor is responsible for infertility and is found in one of three infertile women. ${ }^{3,4}$ The prevalence of pelvic inflammatory disease, genital tract tuberculosis and chronic infection is quite common in our country and hence the incidence of tubal factor in infertile women is high. Conventional diagnostics available were radiographs, hysterosalpingography (HSG), and laparoscopy which were all associated with several risks including invasiveness and exposure to radiation. With each of their own advantages and disadvantages, the available tests for tubal patency include various methods like laparoscopic chromopertubation, hysterosalpingography, saline infusion sonography and the newer techniques like hysterosalpingo contrast sonography (HyCoSy). ${ }^{5,6}$

Hysterosalpingo contrast sonography (HyCoSy) introduced in the early 1980s and is gaining wider acceptance since it combines the principles of both Saline infusion sonography (SIS) and hysterosalpingography (HSG). It is a simple, easy and safe, outpatient procedure that hardly ever requires premedication or hospitalization. 
However, it was not used much in India, as the dye Sonovue used for the procedure was not available here till the recent past. ${ }^{7}$

Laparoscopy with chromopertubation is viewed as the "gold standard" test for tubal assessment in many infertile centres. Adding hysteroscopy to the procedure allows for simultaneous evaluation of the intrauterine cavity and may identify congenital endometrial abnormalities. The advantages being, the ability to evaluate the abdominal cavity and other pelvic structures for an enhanced diagnostic evaluation of other possible etiologies of subfertility and can be used for therapeutic purposes simultaneously. ${ }^{7}$

There is limited literature that has compared HyCoSy with laparoscopy in the evaluation of tubal patency for infertile patients. Hence the current study was undertaken to compare the efficacy of HyCoSy with laparoscopy and chromopertubation in infertile women.

\section{METHODS}

A facility based cross-sectional study was carried out in department of obstetrics and gynecology, Vinayaka Missions Medical College and Hospital, Karaikal, Puducherry, India. The present study was conducted among the patients attending outpatient department with complaints of primary or secondary infertility from August 2016 to March 2017.

Around 42 patients who had such complaints were included in the study after obtaining written and informed consent. Detailed history of the patient was taken; clinical examination and necessary investigations were done.

\section{Inclusion criteria}

- Women in the reproductive age group with infertility

- Women with infertility who have not underwent prior treatment.

\section{Exclusion criteria}

- History of previous abdominal surgical procedures

- History of galactorrhea

- Any history of alcoholism or smoking among couple

- Male factor for infertility.
The study was approved by the institutional human ethics committee, Vinayaka Missions Medical College and Hospital, Karaikal. Written informed consents were obtained from the individuals who were willing to participate in this study. Privacy and confidentiality were maintained throughout the study period. An explicit participant information sheet in both English and the native language (Tamil) was provided to all participants. This document made the subjects understand all the details of the study before providing consent. The study neither required any invasive procedures nor involved any specifically vulnerable population groups.

\section{Statistical analysis}

Data was entered in Microsoft excel and all the analyses were carried out using SPSS version 22. Proportions were used to summarize categorical variables. Chi square test was used to compare proportions. p value $<0.05$ was considered as statistically significant. Sensitivity, specificity, accuracy, and negative and positive predictive values were calculated.

\section{RESULTS}

The current study was conducted among 42 patients attending outpatient department with complaints of primary or secondary infertility in the department of obstetrics and gynecology of a tertiary care hospital. More than half of the study participants belonged to the age group of 26-35 years. Majority of the patients were having primary infertility which constitutes around $73.8 \%$. There exists no statistical significance in age distribution between the type of fertility (Table 1).

In the present study, HyCoSy findings showed 3 false positives among the abnormal findings and 2 false negatives among the normal findings of uterine cavity by hysterolaparoscopy (Table 2).

In left tube findings, HyCoSy ruled out 4 false positives in abnormal findings and 4 false negatives in the normal findings whereas in right tube there were 2 false positives in abnormal findings and 2 false negatives in normal findings with respect to hysterolaparoscopy technique (Table 3 and Table 4). HyCoSy findings of the adnexal pathology showed 12 false positives among the abnormal findings (Table 5).

Table 1: Age group with type of infertility.

\begin{tabular}{|c|c|c|c|c|}
\hline \multirow{2}{*}{$\begin{array}{l}\text { Age group } \\
\text { (years) }\end{array}$} & \multicolumn{2}{|l|}{ Infertility } & \multirow[b]{2}{*}{$\mathbf{N}(\%)$} & \multirow[b]{2}{*}{ Chi-square (p value) } \\
\hline & Primary N (\%) & Secondary N (\%) & & \\
\hline $20-25$ & $5(16.1 \%)$ & $4(36.4 \%)$ & $9(21.4 \%)$ & \multirow{5}{*}{$5.714(0.126)$} \\
\hline $26-30$ & $13(41.9 \%)$ & $2(18.2 \%)$ & $15(35.7 \%)$ & \\
\hline $31-35$ & $13(41.9 \%)$ & $4(36.4 \%)$ & $17(40.5 \%)$ & \\
\hline$>35$ & $0(0.0 \%)$ & $1(9.1 \%)$ & $1(2.4 \%)$ & \\
\hline Total & $31(73.8 \%)$ & $11(26.2 \%)$ & $42(100 \%)$ & \\
\hline
\end{tabular}


Table 2: Uterine cavity findings.

\begin{tabular}{|lllll|}
\hline \multirow{2}{*}{ Procedure } & \multicolumn{3}{l|}{ Hysterolaparoscopy findings } & Total N (\%) \\
\hline \multirow{2}{*}{ HyCoSy } & Abnormal N (\%) & Normal N (\%) & $6(14.3 \%)$ \\
\hline Total & Normal & $3(57.1 \%)$ & $2(5.7 \%)$ & $36(85.7 \%)$ \\
\hline
\end{tabular}

Table 3: Left tube findings.

\begin{tabular}{|lllll|}
\hline \multirow{2}{*}{ Procedure } & \multicolumn{3}{c|}{ Hysterolaparoscopy findings } & Total N (\%) \\
\hline \multirow{2}{*}{ HyCoSy } & Abnormal & $13(76.5 \%)$ & Normal N (\%) & $17(40.5 \%)$ \\
\hline Total & Normal & $4(23.5 \%)$ & $4(16 \%)$ & $25(59.5 \%)$ \\
\hline
\end{tabular}

Table 4: Right tube findings.

\begin{tabular}{|lllll|}
\hline \multirow{2}{*}{ Procedure } & \multicolumn{3}{c|}{ Hysterolaparoscopy findings } & Total N (\%) \\
\hline \multirow{2}{*}{ HyCoSy } & Abnormal & $14(87.5 \%)$ & Normal N (\%) & $16(38.1 \%)$ \\
\hline Total & Normal & $2(12.5 \%)$ & $2(7.7 \%)$ & $26(61.9 \%)$ \\
\hline
\end{tabular}

Table 5: Adnexal pathology.

\begin{tabular}{|lllll|}
\hline \multirow{2}{*}{ Procedure } & \multicolumn{3}{c|}{ Hysterolaparoscopy findings } & Total N (\%) \\
\hline \multirow{2}{*}{ HyCoSy } & Abnormal & $8(40 \%)$ & Normal N (\%) & $8(19 \%)$ \\
\hline Total & Normal & $12(60 \%)$ & $0(0.0 \%)$ & $34(81 \%)$ \\
\hline
\end{tabular}

Table 6: Validity of $\mathrm{HyCoSy}$ with respect to hysterolaparoscopy.

\begin{tabular}{|c|c|c|c|c|c|c|c|c|}
\hline \multirow{2}{*}{\multicolumn{2}{|c|}{ Procedure }} & \multicolumn{7}{|c|}{ Hysterolaparoscopy } \\
\hline & & $\begin{array}{l}\text { True } \\
\text { positive }\end{array}$ & $\begin{array}{l}\text { False } \\
\text { positive }\end{array}$ & $\begin{array}{l}\text { True } \\
\text { negative }\end{array}$ & $\begin{array}{l}\text { False } \\
\text { negative }\end{array}$ & Sensitivity & Specificity & Accuracy \\
\hline \multirow{4}{*}{ HyCoSy } & Uterine cavity findings & 4 & 2 & 33 & 3 & 57.14 & 94.3 & 88.1 \\
\hline & Left tube findings & 13 & 4 & 21 & 4 & 76.5 & 84 & 81 \\
\hline & Right tube findings & 14 & 2 & 24 & 2 & 87.5 & 92.3 & 90.4 \\
\hline & Adnexal pathology & 8 & 0 & 22 & 12 & 40 & 100 & 71.4 \\
\hline
\end{tabular}

All the HyCoSy findings showed excellent specificity (84-100\%) and the sensitivity ranged from 40-87\%. HyCoSy was more specific to rule out the uterine cavity findings which were $94 \%$. The sensitivity was $76 \%$ and $87 \%$ respectively to find out left and right fallopian tube lesions. But it is more specific compared to sensitivity to find out tubal pathology. The hysterolaparoscopy has $100 \%$ specificity to rule out adnexal pathology of uterus with $71 \%$ accuracy (Table 6).

\section{DISCUSSION}

The major causes of infertility include ovulatory dysfunction (20-40\%), tubal and peritoneal pathology $(30-40 \%)$, male factors $(30-40 \%)$, uterine pathology and unexplained infertility. The current study was undertaken to assess the comparative evaluation of hysterosalpingo contrast sonography with laparoscopy for determination of tubal patency in infertility.

Most of the earlier studies showed two-dimensional HyCoSy to be a very good technique to diagnose any uterine cavity lesion giving a sensitivity ranging from $72 \%$ to $100 \%$, specificity of $90 \%$, PPV of $>90 \%$ and NPV of $>80 \%{ }^{5,6,8,9}$

In the present study, sensitivity of the test has been low (75\%) because HyCoSy is an ultrasound based procedure, so it fails to diagnose cavity fibrosis and endometrial lining defects, as thickness of endometrial lining on 
ultrasound does not change till late stages of endometrial lining destruction disorders, so early changes can be appreciated only by direct visualization of the cavity through a hysteroscope in form of pale endometrial lining with decreased vascularity or pin point deep seated ostia in case of pericornual fibrosis.

However, while screening for uterine cavity defects we suggest that in cases with normal HyCoSy, we can even skip hysteroscopy for a while; patient directly can be subjected to more sophisticated assisted reproductive techniques like IUI and IVF can do an endoscopic evaluation of uterine cavity later if required, or if there is a recurrent pregnancy failure. Advanced methods using 3D-HyCoSy have been proposed in which, the full contour of the uterine cavity can be depicted in more than $96 \%$ of cases and mullerian defects can also be studied with a better clarity.

Most of the studies on HyCoSy had a sensitivity ranging from 80 to $90 \%$ i.e., a good overall agreement to laparoscopy except one study by Strandell et al having a low sensitivity of only $27 \%$. $1,5,6,10,11$

In the current study, we have got a slightly lower sensitivity $(76.50 \%)$ for blocked tube on HyCoSy, the possible explanation for this low sensitivity for diagnosing tubal block may be because it is very difficult to see the distal end of the tube and spill from it due to its tortuous course in some cases as supported by other studies. $^{12,13}$ Whereas Hamilton JA et al reported that, in many cases the distal end of the tube was dilated leading to collection of dye there which was misinterpreted as spill on HyCoSy. ${ }^{10}$

Even after having such a big armamentarium of investigations available to diagnose uterine cavity and tubal defects, laparoscopy and hysteroscopy remains the "gold standard" as it not only offers the advantage of being the most accurate diagnostic procedure but can also serve the benefit of being a therapeutic procedure simultaneously.

\section{CONCLUSION}

So in the present study we can conclude that HyCoSy is a good screening method for evaluating uterine cavity lesions and tubal block in infertile women being safe, sensitive, cost effective, non-invasive procedure giving additional information regarding ovarian, adnexal and peritoneal pathology.

It helps in reducing immense burden from medical facilities by sorting out the infertile women, who actually need laparoscopy and hysteroscopy which still remains the gold standard.

Funding: No funding sources Conflict of interest: None declared
Ethical approval: The study was approved by the Institutional Ethics Committee

\section{REFERENCES}

1. World Health Organisation. Manual for the standardized investigation and diagnosis of infertile couple. Cambridge, UK: Cambridge University Press, 2000. Available at: https://www.who.int/reproductivehealth/publications /infertility/0521774748/en/. Accessed on $30^{\text {th }}$ December 2019.

2. Gnoth C, Godehardt E, Frank-Herrmann P, Friol K, Tigges J, Freundl G. Definition and prevalence of subfertility and infertility. Human Reprod. 2005;20(5):1144-7.

3. Guzick DS, Swan S. The decline of infertility: apparent or real?. Fertil Steril. 2006;86(3):524-6.

4. Tournaye H. Evidence based management of male subfertility. Curr Opin Obstet Gynecol. 2006;18:2539.

5. Radić V, Čanić T, Valetić J, Duić Ž. Advantages and disadvantages of hysterosonosalpingography in the assessment of the reproductive status of uterine cavity and fallopian tubes. Eur J Radiol. 2005;53(2):268-73.

6. Socolov D, Lupaşcu IA, Danciu E, Doroftei B, Boian I, Boiculese L, et al. Sonohysterosalpingography versus hysterosalpingography in the evaluation of uterine and tubal infertility. Rev Med Chir Soc Med Nat Iasi. 2009;113(3):803-8.

7. Aggarwal D. Can HyCoSy replace laparoscopy and hysteroscopy as a method to assess tubal patency and uterine cavity lesions? IOSR-JDMS. 2019:18(5):803.

8. Strandell A, Bourne T, Bergh C, Granberg S, Asztely M, Thorburn J. The assessment of endometrial pathology and tubal patency: a comparison between the use of ultrasonography and X-ray hysterosalpingography for the investigation of infertility patients. Ultra Obstet Gynecol. 1999;14(3):200-4.

9. Kupesic S, Plavsic BM. 2D and 3D hysterosalpingocontrast-sonography in the assessment of uterine cavity and tubal patency. Eur J Obstet Gynecol Reprod Biol. 2007;133(1):64-9.

10. Hamilton JA, Larson AJ, Lower AM, Hasnain S, Grudzinskas JG. Evaluation of the performance of hysterosalpingo contrast sonography in 500 consecutive, unselected, infertile women. Human Reprod (Oxford, England). 1998;13(6):1519-26.

11. Reis MM, Soares SR, Cancado ML, Camargos AF. Hysterosalpingo contrast sonography (HyCoSy) with SH U 454 (Echovist) for the assessment of tubal patency. Human Reprod (Oxford, England). 1998;13(11):3049-52.

12. Sladkevicius P, Ojha K, Campbell S, Nargund G. Three-dimensional power Doppler imaging in the assessment of Fallopian tube patency. Ultra Obstet Gynecol. 2000;16(7):644-7. 
13. Chan $\mathrm{CC}, \mathrm{Ng}$ EH, Tang OS, Chan KK, Ho PC. Comparison of three dimensional hysterosalpingocontrast sonography and diagnostic laparoscopy with chromopertubation in the assessment of tubal patency for the investigation of subfertility. Acta Obstet Gynecol Scand. 2005;84(9):909-13.
Cite this article as: Krishnamoorthy G, Perumal A, Boovaragasamy C, Gnanasabai G. Comparative evaluation of hysterosalpingo contrast sonography with laparoscopy for determination of tubal patency in infertility. Int J Reprod Contracept Obstet Gynecol 2020;9:2009-13. 